Research Article

\section{A rare presentation of orbital dermoid: A case study}

\section{Sheetal V Girimallanavar ${ }^{1 *}$, Seema Channabasappa ${ }^{2}$, Balasubrahmanyam Aluri ${ }^{2}$, Divya Rose Cyriac ${ }^{3}$ and Aiswarya Ann Jose ${ }^{3}$}

${ }^{1}$ Assistant Professor, Ophthalmology, MS, DNB, VIMS \& RC, Bengaluru, Karnataka, India ${ }^{2}$ Professor, Ophthalmology, MS, VIMS \& RC, Bengaluru, Karnataka, India

${ }^{3}$ Junior Resident, Ophthalmology, VIMS \& RC, Bengaluru, Karnataka, India

\section{Summary}

Introduction: A dermoid cyst is a developmental choristoma lined with epithelium and filled with keratinized material arising from ectodermal rests pinched off at suture lines. These are the most common orbital tumors in childhood. They are categorized into superficial and deep. Superficial orbital dermoid tumors usually occur in the area of the lateral brow adjacent to the frontozygomatic suture. Infrequently a tumor may be encountered in the medial canthal area [1], which is the second most common site of orbital dermoids. We report a case where a swelling presented in the medial canthal area without involving the lacrimal system.

Case report: A 43 year old lady presented with complaint of swelling near the (RE; Right eye) since 2 years duration. She presented with a solitary $1.5 \mathrm{~cm} \times 1 \mathrm{~cm}$ ovoid, non-tender, non-pulsatile, firm, non-compressible mobile swelling with smooth surface over the medial canthus of right eye. (MRI; Magnetic Resonance Imaging) brain and orbit showed right periorbital extraconal lesion and the (FNAC; Fine Needle Aspiration Cytology) suggested of Dermoid Cyst. RE canthal dermoid cyst excision was done under Local Anasthesia.

Conclusion: Complete surgical excision in to be treatment of choice for dermoids. Since medial canthal mass can involve the lacrimal system, it becomes necessary to perform preoperative assessments using (CT; Computed Tomography), MRI or dacryocystography while planning the surgical approach. Silicone intubation at the beginning of the surgery is an easy and effective way of identifying canaliculi and of preventing canalicular laceration during dermoid excision if the lacrimal system is found to be involved.

\section{More Information}

*Address for Correspondence:

Dr. Sheetal V Girimallanavar, Staff Quarters A4, VIMS \& RC, EPIP Area, Nallurhalli, Whitefield, Bengaluru, Karnataka, Pin Code: 560066; India, Tel: 91 9844792267;

Email: sheetal.girimallanavar@gmail.com

Submitted: July 23, 2021

Approved: August 09, 2021

Published: August 10, 2021

How to cite this article: Girimallanavar SV, Channabasappa S, Aluri B, Cyriac DR, Jose AA A rare presentation of orbital dermoid: $A$ case study. Int J Clin Exp Ophthalmol. 2021; 5: 016-018

DOI: 10.29328/journal.ijceo.1001037

Copyright: (c) 2021 Girimallanavar S, et al. This is an open access article distributed under the Creative Commons Attribution License, which permits unrestricted use, distribution, and reproduction in any medium, provided the original work is properly cited.

Keywords: Dermoid; Medial canthus; Lacrimal system; Silicone tube

(2) Check for updates

(1) OPEN ACCESS

\section{Introduction}

Dermoid tumors in the medial canthal area are rare, but when present commonly adhere to the lacrimal canaliculi [2]. As per our literature review, only five case reports have been issued on orbital dermoid tumors that occurred in the medial canthal area [1-3]. Our case report points at noninvolvement of the lacrimal system, which is a common presentation for medial canthal dermoids because of their close proximity.

The various differential diagnosis for mass in the medial canthal area can be dermoid, epidermoid cyst, lacrimal sac mucocele, hydatid cyst, neurocysticercosis, and prolapsed orbital fat in adults and encephalocele in children [4].

The majority of dermoid cysts are located in the eyelids and most commonly supratemporal region of orbit. These cysts represent $24 \%$ of all orbital and lid masses, $6 \%-8 \%$ of deep orbital masses, and $80 \%$ of cystic orbital lesions [5]. Dermoid cysts may lie dormant for many years before growth and may be located superficially in the eyelid and anterior or deep in the orbit. The treatment is complete surgical excision. The prognosis is excellent, but recurrences with infiltration may follow rupture of the capsule.

\section{Case report}

A 43 year old lady presented with complaint of swelling near the right eye. It was present since 2 years, which was associated with pain and was gradually progressive in size. She denied history of trauma, weight loss, or discharge from the swelling. There was no change in size of swelling with bending or Valsalva manoeuvre. There was no epiphora. The tear meniscus was normal and lacrimal system was found to be patent in both eyes on syringing. Family history was negative for ocular and systemic morbidities. Her general examination and systemic examination was normal. Ocular examination was within normal limits in both eyes except for the swelling near the right eye.

Local examination of the mass: It was a solitary $1.5 \mathrm{~cm} \times 1 \mathrm{~cm}$ ovoid, non-tender, non-pulsatile, firm, non-compressible 
mobile swelling with smooth surface over the medial canthus of right eye. It extended superiorly upto the medial end of eyebrow, inferiorly $0.5 \mathrm{~cm}$ below the medial canthus and medially upto the root of nose. Its edges were well defined and margins were round. Skin over the swelling was uneven, stretched and fixed to the mass. No regional lymphadenopathy was present. MRI brain and orbit showed right periorbital extraconal lesion suggestive of Dermoid Cyst with no extension or involvement of surrounding structures.

\section{Investigations}

- MRI brain and orbit showed right periorbital extraconal lesion suggestive of Dermoid Cyst not involving the adjacent structures (Figure 1).

- FNAC report was suggestive of dermoid cyst.

\section{Treatment}

The patient was diagnosed with Right Periorbital Dermoid Cyst and was educated about her findings, prognosis and need for dermoid cyst excision. RE canthal dermoid cyst excision was done under LA.

Histopathological examination showed a cyst lined by keratinised squamous epithelium with presence of a sebaceous gland. Subepithelially also seen were mesodermal derivatives such as smooth muscle and cartilage which confirmed the diagnosis of dermoid.

Patient did well after surgery. Suture was removed after 1 week. She was followed up for a period of 6 months with no evidence of any possible signs of recurrence.

\section{Discussion}

Dermoid cysts are developmental choristoma originating from aberrant ectodermal tissue, usually develop between 3 to 5 weeks of gestation [6,7]. It is embryonic displacement of epidermis to a subcutaneous location along embryonic lines of closure. They are typically located at the points of fusion

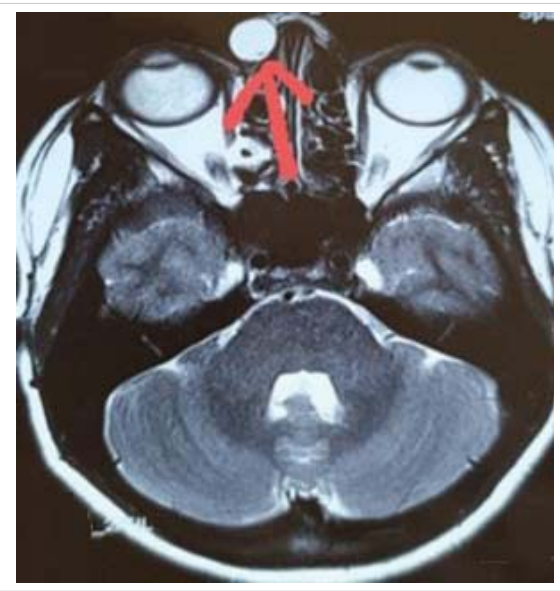

Figure 1: Well defined rounded T2W hyper intense lesion noted in right periorbital extraconal space measuring $15^{*} 10 \mathrm{~mm}$ with no involvement of lacrimal apparatus or extra ocular muscles. of zygomaticofrontal and frontoethmoidal sutures. Hence they are commonly seen along the lateral third of eyebrow or supraorbital ridge $[8,9]$. Hurwitz, et al. $[2,10]$ reported one case of a dermoid tumor that involved the lacrimal excretory system.

Clinically, they present initially as dormant lesions, later as a slowly enlarging, unilateral, painless, firm mass with proptosis, occasionally with motility restriction, and decreased vision. Imaging shows round, well-defined lesions with an enhancing rim that may contain calcium and a lucent center. Complete surgical excision in to be the treatment of choice. The prognosis is excellent, but recurrences with infiltration may follow incomplete excision or rupture of the capsule.

Mass in the medial canthal area can usually involve lacrimal drainage system. Hence preoperative imaging is necessary to assess the extent and involvement of lacrimal system. If the posterior surface of the mass is adherent to the lacrimal system, surgical dissection should be done with utmost care not to injure the lacrimal system as the surgical space is very narrow [2]. Inserting a probe in upper and lower canaliculi helps to minimize the risk of canalicular laceration during the surgery in such cases. However more effective and easy way is bicanalicular silicon intubation prior to the surgery [2].

\section{Conclusion}

Though dermoids in medial canthal area are rare, when they do occur involvement of the lacrimal system is a possibility either by the lesion itself or during surgery, but it can also be possible that lacrimal system at times is not involved as in our study making it a rare presentation. It becomes necessary to rule out lacrimal system involvement prior to the surgery either by CT, MRI or Dacryocystography and plan for silicone intubation of canaliculi before the surgery if found to be involved.

As per our literature review there are just few cases of orbital dermoid having presented in the medial canthal area and most of those cases have involvement of the lacrimal system, ours is probably the first case presenting without lacrimal system involvement.

Declaration of patient consent: The authors declare that the patient has given consent for her relevant clinical information and images to be included in the journal. She has been explained that her name or initial will not be published and her identity will be concealed, but anonymity cannot be guaranteed.

Clinical Pictures: Preoperative images as in figures 2-4.

Pre and Post Surgery images as in figures 5,6.

MRI images Pre and Post Surgery as in figures 7,8. 




Figure 2: Preoperative images.

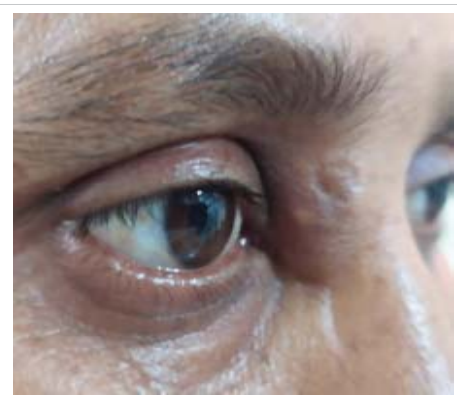

Figure 3: Preoperative images.

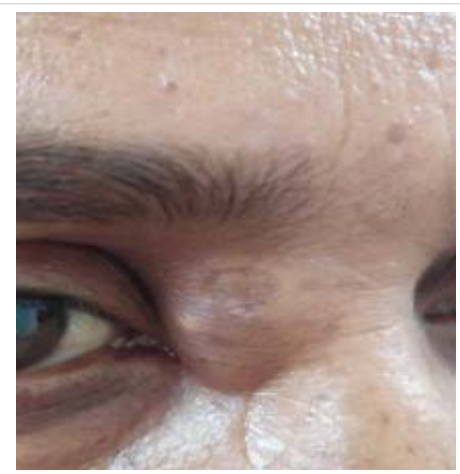

Figure 4: Preoperative images.

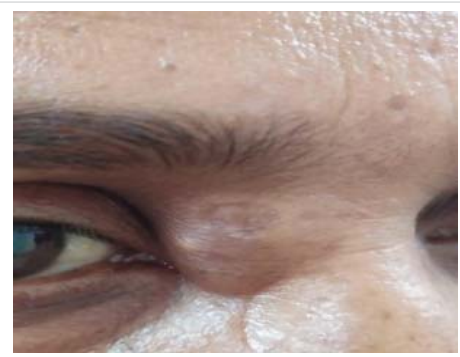

Figure 5: Pre and Post Surgery.

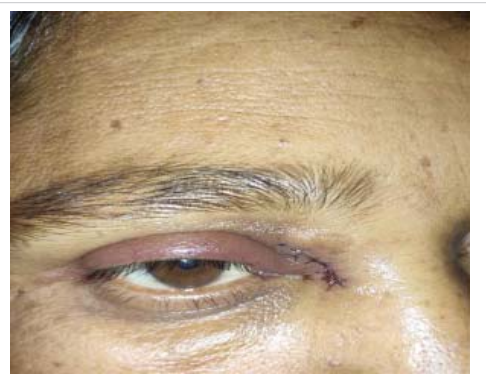

Figure 6: Pre and Post Surgery



Figure 7: MRI image. Pre and Post Surgery.



Figure 8: MRI image. Pre and Post Surgery.

\section{References}

1. Hurwitz JJ, Rodgers J, Doucet TW. Dermoid tumor involving the lacrimal drainage pathway: a case report. Ophthalmic Surg. 1982; 13: 377-379. PubMed: https://pubmed.ncbi.nlm.nih.gov/7099526/

2. Kim NJ, Choung HK, Khwarg SI. Managaement of dermoid tumour in medial canthal area. Korean J Ophthalmol. 2009: 23: 204-206. PubMed: https://pubmed.ncbi.nlm.nih.gov/19794949/

3. DeLaLuzOrozco-CovarrubiasMA,Salazar-LeonJA, Tamayo-SanchezL, Duran-McKinster C, Ruiz-Maldonado R. Dermoid cyst connected with the lacrimal canaliculum. Pediatr Dermatol. 1993; 10: 69-70. PubMed: https://pubmed.ncbi.nlm.nih.gov/8493174/

4. Chawda SJ, Moseley IF. Computed tomography of orbital dermoids: a 20-year review. Clin Radiol. 1999; 54: 821-825. PubMed: https://pubmed.ncbi.nlm.nih.gov/10619299/

5. Yanoff M, Duker JS. Ophthalmology. Second Edition. Mosby: St Louis. 2004; 397-740.

6. Pryor SG, Lewis JE, Weaver AL, Orvidas LJ. Pediatric Dermoid Cyst of Head and Neck. Otolarygol Head Neck Surg. 2005; 132: 938-942. PubMed: https://pubmed.ncbi.nlm.nih.gov/15944568/

7. Russell DS, Rubinstein U. Tumors and tumor like lesions of maldevelopmental origin in, Rubinstein $U$ ed. Pathology of tumours of the nervous system. $5^{\text {th }}$ ed. Baltimore. Md: Williams and Wilkins. 1989; 664-765.

8. Bonavolonta G, Tranfa F, de Concilis C, Strianese D. Dermoid Cyst: 16 years survey. Ophthlmic Plast Reconstr Surg. 1995: 11: 187-192. PubMed: https://pubmed.ncbi.nlm.nih.gov/8541260/

9. Pollard ZF, Harley RD, Calhoun J. Dermoid cysts in children. Pediatrics. 1976: 57: 379-382.

PubMed: https://pubmed.ncbi.nlm.nih.gov/1256948/

10. Rootman J. Disease of the orbit. 2nd ed. Philadelphia: Lippincott Williams \& Wilkins; 2003; 418-423. 